Bangl. J. Vet. Med. (2008). 6 (1): 19-22

\title{
IMMUNOGENICITY OF CAPSULAR EXTRACT PREPARED FROM A LOCAL DUCK ISOLATE OF PASTEURELLA MULTOCIDA
}

\author{
M. Sukul*, M. S. R. Khan, M. T. Rahman and K. Begum
}

Department of Microbiology and Hygiene, Faculty of Veterinary Science, Bangladesh Agricultural University, Mymensingh-2202, Bangladesh

*e-mail: mousumisukul@yahoo.com

\begin{abstract}
The immunogenic response and protection of duck with capsular extract of local isolate of duck cholera organism, i.e. Pasteurella multocida was compared with that of conventional fowl cholera vaccine prepared in Bangladesh Agricultural University, Mymensingh. Feces, liver, heart, lungs, trachea and intestinal swabs were collected from a total of 50 sick and apparently healthy ducks. The duck cholera organisms were isolated and characterized by their cultural, physiochemical, staining properties and laboratory animals and also duck and ducklings inoculation. Capsular antigen was prepared from this isolate. Twelve weeks aged ducks of Jinding breeds were divided into three groups such as A, B and C. Each duck of group A was inoculated with $1 \mathrm{ml}$ of capsular antigen containing $200 \mu \mathrm{l}$ capsular protein and $1 \mathrm{ml}$ of Bangladesh Agricultural University fowl cholera vaccine in group B intramuscularly followed by second vaccination with same vaccine with similar dose and route at 15 days interval in group A and B respectively. Ducks of group C were kept as control. Sera samples of each of the ducks of all the three groups were collected at 7 and 14 days post-vaccination following each of the primary and secondary vaccination. Each of the serum samples of all the three groups of birds was titrated by using passive hemagglutination (PHA) test and results recorded that both the capsular extract $(96.00 \pm 45.25)$ and fowl cholera vaccine (108 \pm 89.37 ) produced more or less similar serological response at two weeks after secondary vaccination. Protection test was performed with all birds of three groups after 21 days of secondary vaccination and the results showed that ducks of both group A and B conferred $100 \%$ protection.
\end{abstract}

Key words: Pasteurella multocida, capsular extract, fowl cholera vaccine, duck, immunogenicity

\section{INTRODUCTION}

Pasteurella multocida (P. multocida) is a gram negative non motile, rod shaped bipolar bacterium causes an economically important disease in duck characterized by an acute septicemia and chronic localized infection (Calnek et al., 1997). Duck cholera (DC) primarily affects adult ducks less than 8 weeks of age. Baki et al. (1991) observed that 11 percent of total mortality of domestic ducks in Bangladesh was due to DC. Various vaccination programs have been reported to control this disease. Khan et al. (1997) reported that a safe and sterile vaccine could protect $40 \%$ in single vaccinated and $80 \%$ in double vaccinated birds when challenged with one infective dose of P. multocida. In Bangladesh, vaccines against fowl cholera/ duck cholera are being prepared in Bangladesh Agricultural University (BAU-FCV) by using duck isolate of P. multocida (PM-38) serotype 1 (X-73) and livestock research institute (LRI-FCV) by using chicken isolate of $P$. multocida and available in local market (Samad, 2000). Although both inactivated and live vaccines are available, inactivated vaccines or bacterins only induced serotype specific protection (Prantner et al., 1990) and live vaccine sometimes cause disease (Carpenter et al., 1988). Therefore researchers are still locking for better vaccines such as subunit vaccines. Keeping this point of focus in mind this study was undertaken to prepare an alternative to conventional whole cell killed vaccine to provide more specific protection against duck cholera. Esmaily et al. (2003) observed that both outer membrane protein and capsular protein are effective immunogens that can be used for the development of subunit vaccine as a substitute of whole cell vaccines currently used against duck cholera infection. This paper describes the immunogenecity of capsular extract prepared from a local duck isolate of Pasteurella multocida in duck. So that it can be used as a subunit vaccine after further investigation. 


\section{MATERIALS AND METHODS}

A total 50 diseased and apparently healthy ducks suspected to be infected with P. multocida were collected from Bangladesh Agricultural University (BAU) poultry farm and Kuliarchar upazila under Kishoregonj district. Feces, liver, heart, lungs, trachea and intestinal swabs were collected. For isolation of the bacteria various cultural media such as nutrient agar (NA), Salmonella-shigella (SS) agar, Brilliant Green agar (BGA), Eosin-Methylene Blue (EMB) agar, MacConkey (MC) agar and Blood agar (BA) were used. For biochemical characterization different types of sugar media such as sucrose, dextrose, maltose, lactose, mannitol and different types of reagents such as methyl red (MR), Voges-Proskauer (V-P), Indol were used. The organism was characterized by Gram's staining, leishman's staining, methylene blue staining.

Capsular extract antigen after separation of capsule from a local field isolate of P. multocida and BAU-FC vaccine prepared by Poultry Biologics Unit, Dept. of Microbiology, Bangladesh Agricultural University, Mymensingh were used for this study. Capsular extract antigen was prepared according to the method suggested by Choudhury et al. (1987). Fresh subculture of $P$. multocida was diluted with PBS and heated at $56^{\circ} \mathrm{C}$ for 30 minutes in hot water bath and the suspension was centrifuged at 4500-6000 rpm for 30 minutes with coarse stone bids. The supernatant was considered as capsular antigen and confirmed by acriflavin test.

A total of 15 twelve weeks old ducks of Jinding breeds with history of no vaccination or infection with duck cholera were purchased and were reared with proper biosecurity. The ducks were divided into three groups such as immunized group (Group A and Group B) and non-immunized control group (Group C). The ducks of group A were immunized with capsular extract antigen at the dose rate of $1 \mathrm{ml}$ containing $200 \mu 1$ capsular protein per duck through intramuscular (IM) route. The ducks of group B were immunized with BAU-FCV at the dose rate of $1 \mathrm{ml}$ containing $5 \times 10^{7} \mathrm{CFU} /$ duck through IM route. Secondary vaccination was given at 15 days after primary vaccination with similar dose and route in group A and B respectively. Sera samples were collected at 7 and 14 days of each immunization. The antibody titer of collected sera and antisera were determined by passive hemagglutination (PHA) test. Protection test was carried out with immunized and control groups after 21 days of secondary vaccination by using same dose $\left(5 \times 10^{7} \mathrm{CFU} / \mathrm{ml}\right)$ and same route of inoculum of virulent $P$. multocida.

\section{RESULTS AND DISCUSSION}

The cultural, staining and physiochemical characterization of the isolated P. multocida from ducks were performed and the immunogenic capability of capsular extract in comparison with the usual fowl cholera vaccine prepared by BAU were determined.

Culture of $P$. multocida in SS agar, BGA and EMB agar yielded small, circular, smooth, translucent, glistening colonies. The growth of $P$. multocida in blood agar yielded small colonies with whitish opaque circular and translucent appearance with no hemolysis. The organisms revealed Gram's negative cocco-bacillary shape and bipolar characteristics. Choudhury et al. (1985) and Cowan and Steel (1985) isolated and identified P. multocida on the basis of morphology, staining, cultural, biochemical and serological characteristics.

Biochemical tests of the isolated organisms showed complete fermentation of dextrose, sucrose and mannitol but did not ferment maltose and lactose which are the characteristics of P. multocida according to Calnek et al. (1997) and Indol and MR-VP tests were found to be negative for the isolates of P. multocida.

It was observed that the mean PHA antibody titers of ducks in group A (44.8 \pm 17.52$)$ which were immunized with capsular extract antigen and group B $(54.4 \pm 44.68)$ which were immunized with BAU-FC vaccine differed slightly in comparison to non-immunized control group $\mathrm{C}(\leq 4 \pm 0.00)$ at the age of 14 days (Table 1$)$. The preimmunization PHA titers of sera samples of ducks of all the groups were found to be a mean of $\leq 4.0 \pm 0.00$ which was closely related to Mondal et al. (1988). The primary immunization induced slight rise of PHA titers ranging from 8 to 16 at 7 days post-immunization and a titer ranging from 32 to 64 at 14 days postimmunization in ducks of both the group A and group B in most cases (Table 1). The findings were closely related with Coates et al. (1977) and Mondal et al. (1988).

From Table 1, it was revealed that the mean PHA antibody titer at 14 days after secondary immunization were much higher in both the group A $(96.00 \pm 45.25)$ and group B $(108.8 \pm 89.37)$ immunized with capsular extract antigen and BAU-FC vaccine in comparison to their respective values of 14 days after primary immunization and control. 
Table 1. Passive haemagglutination titers of sera of ducks immunized with primary and secondary dose of capsular extract antigen and fowl cholera vaccine

\begin{tabular}{|c|c|c|c|c|c|c|c|c|c|}
\hline \multirow{3}{*}{$\begin{array}{l}\text { Group } \\
(\mathrm{n}=5)\end{array}$} & \multirow[t]{3}{*}{ Types } & \multirow{3}{*}{$\begin{array}{l}\text { Dose and } \\
\text { Route of } \\
\text { inoculation }\end{array}$} & \multirow{3}{*}{$\begin{array}{l}\text { Pre-immunization } \\
\text { (0 day) }\end{array}$} & \multicolumn{4}{|c|}{ Post-immunization PHA titer } & \multirow{2}{*}{\multicolumn{2}{|c|}{$\begin{array}{l}\text { Challenge } \\
\text { protection }\end{array}$}} \\
\hline & & & & \multicolumn{2}{|c|}{ Post-primary } & \multicolumn{2}{|c|}{ Post-secondary } & & \\
\hline & & & & 7 days & 14 days & 7 days & 14 days & & \\
\hline A & $\begin{array}{l}\text { Capsular } \\
\text { antigen }\end{array}$ & $1 \mathrm{ml} \mathrm{IM}$ & $\begin{array}{l}\leq 4 \\
\leq 4 \pm 0.00\end{array}$ & $\begin{array}{l}8-16 \\
12.8 \pm 4.38\end{array}$ & $\begin{array}{l}32-64 \\
44.8 \pm 17.52\end{array}$ & $\begin{array}{l}16-128 \\
51.2 \pm 47.19\end{array}$ & $\begin{array}{l}32-128 \\
96.0 \pm 45.25\end{array}$ & 05 & 100 \\
\hline B & $\begin{array}{l}\text { BAU- } \\
\text { FCV }\end{array}$ & $1 \mathrm{ml} \mathrm{IM}$ & $\begin{array}{l}\leq 4 \\
\leq 4 \pm 0.00\end{array}$ & $\begin{array}{l}8-32 \\
16 \pm 9.79\end{array}$ & $\begin{array}{l}16-128 \\
54.4 \pm 44.68\end{array}$ & $\begin{array}{l}32-128 \\
70.4 \pm 35.05\end{array}$ & $\begin{array}{l}32-256 \\
108.8 \pm 89.37\end{array}$ & 05 & 100 \\
\hline $\mathrm{C}$ & Control & - & $\begin{array}{l}\leq 4 \\
\leq 4 \pm 0.00\end{array}$ & $\begin{array}{l}\leq 4 \\
\leq 4 \pm 0.00\end{array}$ & $\begin{array}{l}\leq 4 \\
\leq 4 \pm 0.00\end{array}$ & $\begin{array}{l}\leq 4 \\
\leq 4 \pm 0.00\end{array}$ & $\begin{array}{l}\leq 4 \\
\leq 4 \pm 0.00\end{array}$ & 00 & 000 \\
\hline
\end{tabular}

$\mathrm{n}=$ Number of ducks.

It was observed that PHA titers ranging from 64 to 128 at 7 days post-immunization and a titer ranging from 128 to 256 at 14 days post-immunization in ducks of both the Group A and group B in most cases. The findings were correlated with the observation of Collins (1977), Dua and Masheswaran (1978), Kodama et al. (1983) and Mondal et al. (1988). These authors reported that inoculation of single dose of fowl cholera vaccine resulted in slight detectable rise of antibody titers and introduction of second dose of vaccine 7 days later brought about an increase in such titers. In this respect Choudhury et al. (1987) observed that immune response of birds following single and dual vaccination indicated that dual vaccination at two weeks interval were more effective than single vaccination. Mondal et al. (1988) reported that sera possessing PHA titer of 32 to 64 at the end of $2^{\text {nd }}$ weeks of primary vaccination had a triggering effect at the stage following another dose of vaccine which was found to be highest ranging from 128 to 256 at the end of $7^{\text {th }}$ week post-vaccination. Thereafter PHA titer started to decline gradually from the $9^{\text {th }}$ week and continued up to 25 weeks post-vaccination.

From the study it was observed that there was a slight variation in the pattern of antibody production in groups $\mathrm{A}$ and $\mathrm{B}$ where the titer was slightly lower in group A. The reason for such variation might be due to individual antigenic variation among the vaccine strain or any stress condition in experimental birds.

The challenged test revealed that both the capsular extract and BAU-FC vaccine conferred $100 \%$ protection $(\mathrm{P}<0.01)$ against challenge infection (Table 1). Carter (1972) observed that capsular antigen produced better immunity than somatic antigen. Borisendova (1978) observed that capsular antigen plays an important role in the immunogenicity. In case of capsular extract antigen one duck was affected after challenge exposure but gradually the infection subsided. It may be due to stress or any other infection of the duck (Table 1). All the birds of control group developed clinical signs of duck cholera. The present study indicates that both the capsular extract and BAU-FC vaccines stimulated similar and satisfactory humoral immune responses that can withstand a virulent challenge infection.

\section{REFERENCES}

1. Baki MA, Islam MP, Das PM, Karmaker PK and Mondal MMH (1991). Pathology of duck cholera in natural and experimental infection. Bangladesh Journal of Microbiology 8: 1-4.

2. Borisendova AN (1978). Role of somatic and capsular antigens of P. multocida in the immunological specificity of vaccines. Veterinary Moscow 5: 40-42.

3. Calnek BW, Barnes HJ, Beard CW, McDougald LR and Saif YM (1997). Diseases of Poultry. $10^{\text {th }}$ edn., Iowa State University Press, Ames, Iowa . pp. 143-150.

4. Carpenter TE, Snipe KP, Wallis D and McCapes RH (1988). Epidemiology and financial impact of fowl cholera in turkeys: a retrospective analysis. Avian Diseases 32: 16-23.

5. Carter GR (1972). Improved haemagglutination test for identifying type 'A' strain of P. multocida. Applied Microbiology 24: 162-163. 
6. Choudhury KA, Amin MM, Rahman A and Ali MR (1985). Investigation of natural outbreak of fowl cholera. Bangladesh Veterinary Journal 19: 49-56.

7. Choudhury KA, Amin MM, Sarker AJ and Ahamed AR (1987). Immunization of chickens against fowl cholera with oil-adjuvanted broth culture vaccine. Bangladesh Veterinary Journal 21: 63-73.

8. Coates RS, Jensen JM and Brown ED (1977). The response of turkey to varying doses of lives oral P. multocida vaccine. Poultry Science 56: 273-276.

9. Collins FM (1977). Mechanisms of acquired resistance of $P$. multocida. Cornell Veterinarian 67: 103-167.

10. Cowan ST and Steel KS (1985). Manual for identification of bacteria. $2^{\text {nd }}$ edn., Cambridge University Press, Cambridge, London.

11. Dua SK and Masheswaran SK (1978). Studies of $P$. multocida between levels of immunity induced by various challenge. Avian Diseases 22: 748-764.

12. Esmaily F, Jabari AR, Sotoodehnia A and Jula GRM (2003). The immunological responses to various cell all fractions of $P$. multocida in chicken. Archives of Razi Institute 56: 59-70.

13. Khan MAHNA, Das PM, Choudhury KA and Islam MR (1997). Pathology of experimentally induced fowl cholera in chickens. Bangladesh Veterinary Journal 31: 28-34.

14. Kodama H, Matsumoto M, Fuquay JI and Syuto B (1983). Soluble fraction of P. multocida: Their protective qualities against fowl cholera in turkeys. Avian Diseases 27: 283-291.

15. Mondal SK, Choudhury KA, Amin MM, Rahman MM and Sarker AJ (1988). Humoral immune response in chickens induced by alum precipitated fowl cholera vaccine. Bangladesh Veterinary Journal 22: 63-69.

16. Prantner MM, Hermon BG, Glisson JR and Mahaffey EA (1990). The pathogenesis of P. multocida serotype A infection in turkeys: a comparison of two vaccine strains and a field isolate. Avian Diseases 34: 260-266.

17. Samad MA (2000). Veterinary Practitioner's Guide. $1^{\text {st }}$ edn., LEP Publication, No. 07, BAU Campus, Mymensingh. 